\title{
Genetic polymorphisms modifying oxidative stress are associated with disease activity in rheumatoid arthritis patients
}

\author{
Petra Bohanec Grabar ${ }^{\mathrm{a}}$, Dušan Logar ${ }^{\mathrm{b}}$, Matija Tomšič ${ }^{\mathrm{b}}$, Blaž Rozman ${ }^{\mathrm{b}}$ and Vita Dolžan ${ }^{\mathrm{a}, *}$ \\ ${ }^{\mathrm{a}}$ University of Ljubljana, Faculty of Medicine, Institute of Biochemistry, Ljubljana, Slovenia \\ ${ }^{\mathrm{b}}$ University Medical Centre Ljubljana, Department of Rheumatology, Ljubljana, Slovenia
}

\begin{abstract}
Reactive oxygen and nitrogen species are involved in the pathology of rheumatoid arthritis (RA). Polymorphisms in genes coding for superoxide dismutases (SOD2 and SOD3), catalase (CAT), tumor necrosis factor-alpha (TNFA) and inducible NO synthase (NOS2A) may influence RA activity. We determined SOD2 Ala-9Val, SOD3 Arg213Gly, CAT C-262T, TNFA G-308A, TNFA C-857T and NOS2A (CCTTT) $n$ polymorphisms in 327 RA patients. Carriers of CAT -262T and TNFA -308A allele had lower mean disease activity score of 28 joint count (DAS28) values than patients with CAT -262CC and TNFA -308GG genotypes ( $p=0.014$ and $p=0.046$, respectively). Patients with the combination of CAT -262T and TNFA -308A allele had lower mean DAS28 values and a higher probability for low disease activity than non-carriers $(p=0.003, \mathrm{OR}=3.585,95 \%$ CI $=1.538-8.357)$. Our results suggest that CAT and TNFA polymorphisms alone and in combination influence the activity of RA.
\end{abstract}

Keywords: Reactive oxygen species, rheumatoid arthritis, genetic polymorphism, disease activity

\section{Introduction}

Rheumatoid arthritis (RA) is a systemic autoimmune disease characterized by chronic inflammation. Activated neutrophils in the inflammed joints produce numerous cytokines, including tumor necrotic factoralpha $(\mathrm{TNF} \alpha)$ [1]. TNF $\alpha$ stimulates the phagocytic cells to undergo an oxidative blast and generate reactive oxygen species (ROS) and activates the inducible NO synthase (iNOS) to produce NO [2,3]. In the presence of NO highly toxic reactive nitrogen species (RNS) may be formed by ROS. Both ROS and RNS cause damage on DNA, proteins and lipids (reviewed in [4]).

Since ROS and RNS damage the cartilage and the components of the extracellular matrix, they may be directly involved in the pathology of RA (reviewed

*Corresponding author: Vita Dolžan, University of Ljubljana, Faculty of Medicine, Institute of Biochemistry, Vrazov trg 2, 1000 Ljubljana, Slovenia. Tel.: +386 15437670; Fax: +386 15437641; E-mail: vita.dolzan@mf.uni-lj.si. in [5]). To prevent cellular damage, complex defense mechanisms including many enzymes, proteins and antioxidants have evolved. Among them are antioxidant enzymes such as superoxide dismutases (SOD) that convert superoxide into hydrogen peroxide $\left(\mathrm{H}_{2} \mathrm{O}_{2}\right)$ and catalase (CAT) that further decomposes $\mathrm{H}_{2} \mathrm{O}_{2}$ into water and oxygen. SOD isoenzyme family has at least three members; MnSOD, a mitochondrial enzyme that is expressed in all cells types, cytosolic $\mathrm{CuZn}$ SOD and extracellular SOD (EC-SOD) that is tissue specific. Numerous single nucleotide polymorphisms (SNPs) in the genes coding for antioxidant enzymes have been described that may modify the ROS detoxification capacity. The most frequently studied SNP in the gene coding for MnSOD (SOD2) causes Ala to Val substitution (Ala-9Val, rs4880) and thus reduces mitochondrial import of the enzyme due to altered protein secondary structure [6]. A SNP in the gene coding for EC-SOD (SOD3) that causes Arg to Gly substitution (Arg213Gly, rs1799895) alters the heparinbinding domain, which anchors the enzyme in the cell 
membrane [7]. On the other hand, promoter SNP CAT $\mathrm{C}-262 \mathrm{~T}$ (rs1001179) influences the gene expression in red blood cells both at mRNA and enzyme levels [8].

Polymorphisms that may influence the intensity of the inflammatory processes have also been described in genes coding for pro-inflammatory factors that stimulate ROS and RNS production such as TNF $\alpha$ and iNOS. In the transcriptional regulation region of the gene coding for TNF $\alpha$ (TNFA) several SNPs are known, among which G-308A (rs1800629) and C-857T (rs1799724) may have an affect on the mRNA and protein level [9, 10]. In the promoter region of the gene coding for iNOS (NOS2A) a variable number of CCTTT pentanucleotide repeat $\left((\mathrm{CCTTT})_{n}\right)$ has been described that may be important in the regulation of NOS2A transcription [11].

As SNPs in the antioxidant enzymes alter enzymes' structure, substrate specificity or activity they may modify the inter-individual variability in the defense capacity against oxidative stress, while polymorphisms in the pro-inflammatory factors that are directly involved in the inflammation may modify the pathogenesis of the disease. In this way, polymorphisms in the antioxidant enzymes and pro-inflammatory factors may influence the activity of RA. In this study we investigated if polymorphisms of SOD2, SOD3, CAT, TNFA and NOS2A influence the activity of RA. In addition, we investigated the potential interactions between the studied SNPs and assessed the influence of the combination of polymorphic genotypes on the activity of RA.

\section{Materials and methods}

\subsection{Patients}

The study population consisted of a group of 327 unrelated Central European Caucasian RA patients that fulfilled the criteria for the diagnosis [12]. Patients were treated at the Department of Rheumatology, University Medical Centre Ljubljana, Slovenia and were enrolled from September 2005 to September 2007. All the patients were treated with one or more disease modifying antirheumatic drugs (DMARDs), which included methotrexate (MTX), leflunomide, chloroquine, sulfasalazine, injectable gold, cyclosporine and others. Therapy was administered as clinically indicated.

All the patients gave their written informed consent for participating in the study. The study was approved by the Slovenian Ethics Committee for Research in Medicine and was carried out according to the Helsinki Declaration.

\subsection{Clinical and laboratory assessments}

Erythrocyte sedimentation rate (ESR; $\mathrm{mm} / \mathrm{h}$ ) and Creactive protein $(\mathrm{CRP} ; \mathrm{mg} / \mathrm{L})$ were measured at the entry of the patients into the study. The disease activity score of 28 joint count (DAS28) was calculated for each patient using the calculation which included the number of tender and swollen joints, ESR and patients' global assessment of general health expressed on visual analogue scale [13]. Patients with DAS28 less than 3.2 were classified into the low activity group, while patients with DAS28 values 3.2 and more were referred to as others. In the selected 100 RA patients receiving low-dose MTX monotherapy two DAS28 scores of two consecutive visits within three months time (at the inclusion in the study and at month 3 of the follow-up) were obtained and mean DAS28 values were calculated to evaluate the disease activity over time.

Rheumatoid factor (RF) was determined by the Waaler- Rose and Latex agglutination method and the presence of anti-citrullinated peptide antibodies (anti$\mathrm{CCP}$ ) was assessed with the ELISA method using Immunoscan RA anti-CCP test kit (Euro-Diagnostica, Malmö, Sweden).

Cigarette smoking status was obtained for each patient by a questionnaire. Data on the disease and treatment duration, body mass index (BMI), erosive changes of hands and feet observed on X-rays were collected from individual patient's files.

\subsection{Genotyping}

Genomic DNA was isolated from peripheral blood leukocytes using a standard salting-out procedure and a Qiagen FlexiGene kit (Qiagen GmbH, Germany) [14]. Polymerase chain reaction (PCR) amplification with a fluorescent labeled primer followed by a capillary electrophoresis was used for NOS2A (CCTTT) $n$ genotyping as previously described [15]. To determine CAT C-262T polymorphism the region encompassing the polymorphic site was amplified and PCR product was further digested with SmaI (New England Biolabs) as previously described [8]. To determine the SOD2 Ala-9Val, SOD3 Arg213Gly and TNFA C-857T polymorphisms TaqMan SNP genotyping assays were used (C_8709053_10, C 2307506_10 and C_11918223_10, respectively, AB assay, Applied Biosystems, Foster City, California, USA). To determine TNFA G-308A polymorphism a custom TaqMan assay (ABI, Foster City, California, USA) was designed and kindly provided by dr. Rupreht 
from Blood Transfusion Centre, Ljubljana, Slovenia. Primer and probe sets for were designed as follows F: 5'-CTGGTCCCCAAAAGAAATGGA-3', R: 5'GGGCCACTGACTGATTTGT-3'; -308G probe VIC5'-CCCGTCCTCATGCC-3', -308A probe FAM-5'CCCGTCCCCATGCC-3'. Real time PCR was performed under universal conditions on ABI 7500 in a $5 \mu \mathrm{L}$ reaction mix containing $0.125 \mu \mathrm{L}$ of the corresponding genotyping assay, $2.5 \mu \mathrm{L}$ of TaqMan Universal PCR Master Mix (ABI, Foster City, California, USA) and a $100 \mathrm{ng}$ of DNA. Prior to genotyping TaqMan assays were validated on 100 samples with a known genotype.

\subsection{Statistical analyses}

Multiple linear regression analysis with the adjustment for sex, age, BMI, disease and treatment duration and RF/anti-CCP seropositivity was used to determine the influence of the genetic polymorphisms on DAS28. Regression coefficient was given by B value with standard error (SE). Binary logistic regression analysis with the same adjustments was used to express the probability for low disease activity as an odds ratio (OR) with $95 \%$ confidence intervals (CI). All statistical analyses were done using SPSS for Windows version 14.0.1 software (Statistical Package for the Social Sciences, Chicago, IL). Hardy-Weinberg equilibrium and linkage disequilibrium analyses were performed using Arlequin version 3.1 [16]. Linkage disequilibrium measures are given with $r^{2}$. Correction for potentional multiple testing errors was performed using Holm's procedure. The power calculations were done using $\mathrm{G}^{*}$ Power version 3.0.3 [17]. Our study had a $90 \%$ statistical power to detect medium effect sizes (0.3-0.5) with an alpha level of 0.05 .

\section{Results}

In our study we investigated the influence of SNPs in the genes coding for antioxidant enzymes and proinflammatory factors on the activity of RA in a group of 327 patients. Demographic and clinical characteristics of the patients are presented in Table 1 . The female to male sex ratio was 6.4 to 1 . The majority of the patients was treated with MTX $(57.2 \%)$, followed by leflunomide $(33.3 \%)$, sulfasalazine $(22.3 \%)$ and cloroquine $(18.3 \%)$. Approximately $18 \%$ of the patients were treated with corticosteroids and $9 \%$ were treated with biologics. Sex, age, BMI and RF/anti-CCP
Table 1

Baseline characteristics of RA patients $(\mathrm{N}=327)$

\begin{tabular}{lc}
\hline Characteristic & Baseline value \\
\hline Sex: male N (\%) & $44(13.5)$ \\
female & $283(86.5)$ \\
Median age [years] (range) & $60(51-59)$ \\
Median BMI (range) & $24.5(22.3-28.0)$ \\
Past or current smokers & $132(40.4)$ \\
Median disease duration [months] (range) & $84(42-156)$ \\
RF/anti-CCP seropositivity* N (\%) & $263(80.9)$ \\
Presence of erosions* N (\%) & $251(79.2)$ \\
Mean DAS28 (SD) & $4.2(1.3)$ \\
Median ESR [mm/h] (range) & $24.0(15.0-36.0)$ \\
CRP positivity* (CRP $\geqslant 5$ mg/L), N (\%) & $184(56.6)$ \\
Median treatment duration [months] (range) & $29.0(11.5-56.0)$ \\
DMARDs treatment, N (\%): MTX & $187(57.2)$ \\
Leflunomide & $109(33.3)$ \\
Sulfasalazine & $73(22.3)$ \\
Cloroquine & $60(18.3)$ \\
Other DMARD & $54(16.5)$ \\
\hline
\end{tabular}

Median values are given with the range of p25-p75.

${ }^{*} \mathrm{RF} / \mathrm{anti}-\mathrm{CCP}$ seropositivity, the presence or absence of erosions observed on X-rays of hands and feet and CRP positivity was assessed in 325,325 and 317 patients, respectively.

seropositivity did not influence the mean DAS28 values. A correlation between the disease duration and DAS28 as well as treatment duration and DAS28 was found $(p=0.001, \mathrm{~B}=0.002 \pm 0.001$ and $p=0.003$, $\mathrm{B}=-0.006 \pm 0.002$, respectively). An association of the disease duration, RF and/or anti-CCP seropositivity, smoking status with the presence of bone erosions was observed ( $p<0.001, p=0.026$ and $p=0.026$, respectively).

We analyzed the following polymorphisms: SOD2 Ala-9Val, SOD3 Arg213Gly, CAT C-262T, TNFA G308A, TNFA C-857T and NOS2A $\left(\right.$ CCTTT) ${ }_{n}$. The observed frequencies of the studied polymorphisms did not deviate from the Hardy-Weinberg equilibrium ( $p>$ 0.276). Only one subject with SOD3 213Arg/Gly genotype was detected so the association of this SNP with disease activity was not assessed. We detected from 7 to 16 CCTTT repeats in the NOS2A promoter region. For further analyses we stratified RA patients according to the NOS2A genotypes into carriers of short ( $n=$ $7-11)$ and carriers of at least one long ( $n=12-16)$ NOS2A CCTTT repeat. We found no individual with TNFA -308 AA and TNFA -857 TT genotype however, linkage disequilibrium between TNFA -308 and -857 loci was not strong $\left(r^{2}=0.0386\right)$. Among all the patients, five were excluded from the analyses due to the inefficient PCR amplification of TNFA -308 (one), CAT (two) and NOS2A (three).

We assessed the influence of SOD2 Ala-9Val, CAT C-262T, TNFA G-308A, TNFA C-857T and NOS2A 
Table 2

The association of genetic polymorphisms with disease activity in RA patients

\begin{tabular}{|c|c|c|c|c|c|}
\hline \multirow[t]{2}{*}{ Genotype } & & \multirow[t]{2}{*}{$\mathrm{N}(\%)$} & \multicolumn{3}{|c|}{ Disease activity } \\
\hline & & & $\begin{array}{c}\text { Mean DAS28 } \\
(\mathrm{SD})\end{array}$ & $\begin{array}{c}\text { Low } \\
\mathrm{N}(\%) \\
\end{array}$ & $\begin{array}{l}\text { Other } \\
\mathrm{N}(\%) \\
\end{array}$ \\
\hline \multirow[t]{2}{*}{ SOD2 -9 } & Ala/Ala & $90(27.5)$ & $4.1(1.3)$ & $19(30.6)$ & $71(26.8)$ \\
\hline & $\mathrm{Ala} / \mathrm{Val}$ or $\mathrm{Val} / \mathrm{Val}$ & $237(72.5)$ & $4.3(1.3)$ & $43(69.4)$ & $194(73.2)$ \\
\hline \multirow[t]{2}{*}{ CAT -262} & $\mathrm{CC}$ & $175(53.8)$ & $4.4(1.3)^{\dagger}$ & $25(41.0)$ & $150(56.8)$ \\
\hline & $\mathrm{CT}$ or TT & $150(46.2)$ & $4.0(1.2)^{\dagger}$ & $36(59.0)^{\#}$ & $114(43.2)^{\#}$ \\
\hline \multirow[t]{2}{*}{ TNFA -308 } & GG & $227(69.6)$ & $4.3(1.2)^{\ddagger}$ & $39(62.9)$ & $188(71.2)$ \\
\hline & GA or AA & $99(30.4)$ & $4.0(1.3)^{\ddagger}$ & $23(37.1)^{¥}$ & $76(28.8)^{¥}$ \\
\hline \multirow[t]{2}{*}{ TNFA -857} & $\mathrm{CC}$ & $231(70.6)$ & $4.2(1.3)$ & $46(74.2)$ & $185(69.8)$ \\
\hline & $\mathrm{CT}$ or TT & $96(29.4)$ & $4.3(1.3)$ & $16(25.8)$ & $80(30.2)$ \\
\hline \multirow[t]{2}{*}{ NOS2A } & Short repeat $(8-11)$ & $77(23.8)$ & $4.1(1.4)$ & $19(30.6)$ & $58(22.1)$ \\
\hline & At least one long repeat (12-16) & $247(76.2)$ & $4.2(1.2)$ & $43(69.4)$ & $204(77.9)$ \\
\hline
\end{tabular}

*Five samples were excluded from the analyses due to insufficient PCR amplification of TNFA -308 (1), CAT (2) and NOS2A (3).

${ }^{\dagger} p=0.014 ;{ }^{\ddagger} p=0.046 ;{ }^{\#} p=0.008, \mathrm{OR}=2.252,95 \% \mathrm{CI}=1.238-4.097 ;{ }^{¥} p=0.156, \mathrm{OR}=1.576,95 \% \mathrm{CI}$

$=0.841-2.955$.

$p$ values were corrected for sex, age, BMI, disease and treatment duration and RF/anti-CCP seropositivity.

Table 3

The association of the combination of polymorphic genotypes with disease activity in RA patients

\begin{tabular}{|c|c|c|c|c|}
\hline \multirow[t]{2}{*}{ Genotype combination } & \multirow[t]{2}{*}{$\mathrm{N}(\%)$} & \multicolumn{3}{|c|}{ Disease activity } \\
\hline & & $\begin{array}{c}\text { Mean DAS28 } \\
\text { (SD) }\end{array}$ & $\begin{array}{c}\text { Low } \\
\text { N (\%) }\end{array}$ & $\begin{array}{l}\text { Other } \\
\mathrm{N}(\%)\end{array}$ \\
\hline \multicolumn{5}{|c|}{ TNFA -308 GA+AA and CAT-262 CT+TT } \\
\hline Non-carriers & $283(87.1)$ & $4.3(1.3)^{\dagger}$ & $46(75.4)$ & $237(89.8)$ \\
\hline Carriers & $42(12.9)$ & $3.7(1.1)^{\dagger}$ & $15(24.6)^{\ddagger}$ & $27(10.2)^{\ddagger}$ \\
\hline
\end{tabular}

$(\mathrm{CCTTT})_{n}$ on disease activity as presented in Table 2 . We observed that the carriers of CAT $-262 \mathrm{~T}$ polymorphic allele had significantly lower mean DAS28 values as compared to the patients with CAT -262CC genotype $(\mathrm{DAS} 28=4.0 \pm 1.2$ vs. DAS28 $=4.4 \pm 1.3, p=$ 0.014 ). Also the patients with TNFA -308GA or AA genotypes had significantly lower mean DAS28 values as compared to the patients with TNFA -308GG genotype $(\mathrm{DAS} 28=4.0 \pm 1.3$ vs. DAS28 $=4.3 \pm 1.2, p=$ 0.046). When we stratified the patients into two disease activity groups (low: DAS2 $<3.2$ and other: DAS28 values $\geqslant 3.2$ ), we observed that the patients with CAT 262CT or TT genotypes had a 2.3-fold higher probability for low disease activity as compared to the patients CAT -262CC genotype ( $p=0.008, \mathrm{OR}=2.252,95 \%$ $\mathrm{CI}=1.238-4.097)$. On the other hand, SOD2 Ala9Val, TNFA C-857T and NOS2A (CCTTT) ${ }_{n}$ polymorphisms were not significantly associated with disease activity. After the correction for multiple testing, the statistical significance was lost for all except the latter result $(p=0.04)$.
Further on, we investigated how the presence of two or more genotypes that contributed to lower mean DAS28 values influenced disease activity as shown in Table 3. We observed that the carriers of the combination of CAT -262T and TNFA -308A polymorphic allele had significantly lower mean DAS28 values as compared to the non-carriers of this allele combination $(\mathrm{DAS} 28=3.7 \pm 1.1$ vs. DAS28 $=4.3 \pm 1.3, p=$ 0.003). When we stratified the patients into two disease activity groups, we observed that the carriers of the combination of CAT -262T and TNFA -308A polymorphic allele had a 3.6-fold higher probability for low disease activity as compared the non-carriers of this allele combination $(p=0.003, \mathrm{OR}=3.585,95 \% \mathrm{CI}=$ 1.538-8.357).

We obtained similar results when only female patients or when only RF and/or anti-CCP positive patients were included in the analyses (data not shown).

Finally, we tested the strength of our observations on the selected group of RA patients receiving low-dose MTX monotherapy $(\mathrm{N}=100)$. In this subgroup two 
DAS28 scores of two consecutive visits within three months time were assessed and mean DAS28 was 3.8 (0.7). Similarly to the whole RA cohort, the carriers of CAT -262T and TNFA -308A allele had lower mean DAS28 values than the patients with CAT $-262 \mathrm{CC}$ and TNFA -308GG genotypes (DAS28 $=3.7 \pm 0.7$ vs. DAS28 $=4.0 \pm 0.7, p=0.010$ and DAS28 $=3.6 \pm$ 0.8 vs. DAS $28=4.0 \pm 0.7, p=0.007$, respectively). The carriers of CAT $-262 \mathrm{~T}$ allele had higher probability for low disease activity than the patients with CAT 262CC genotype $(p=0.007, \mathrm{OR}=7.675,95 \% \mathrm{CI}=$ 1.743-33.796). The carriers of both CAT $-262 \mathrm{~T}$ and TNFA -308A allele had lower mean DAS28 values and higher probability for low disease activity than the noncarriers $(\mathrm{DAS} 28=3.2 \pm 0.7$ vs. DAS28 $=4.0 \pm 0.7$, $p<0.001$ and $p=0.004, \mathrm{OR}=13.363,95 \% \mathrm{CI}=$ 2.331-76.594, respectively).

\section{Discussion}

In a well documented group of RA patients we have shown that SNPs in the antioxidant enzymes and proinflammatory factors may be associated with the activity of RA. We observed that CAT C-262T and TNFA G-308A polymorphisms separately or in combination are significantly associated with RA activity.

There is an extensive evidence for the role of oxidative stress in RA (reviewed in [4]). Common SNPs in the genes coding for enzymes involved in the defense against oxidative stress like SOD2 and CAT may modify the ROS detoxification capacity and hence influence RA activity. We observed a significant association of CAT C-262T polymorphism with disease activity, but no association with SOD2 Ala-9Val was found. Our observation that the carriers of CAT -262T polymorphic allele had lower disease activity than the patients with CAT -262CC genotype is in a good agreement with the finding that CAT promoter SNP results in an increased level of the enzyme in erythrocytes [8], but not with the results of a previous study reporting a lower catalase activity in the carriers of the CAT -262T allele [18, 19]. To our knowledge, no study on the association of SOD2 Ala-9Val and CAT C-262T polymorphism with RA activity has been reported to date. A study on the influence of CAT C-262T polymorphism on the susceptibility and severity of RA in Korean population was reported but observed no significant associations [20]. Also no association of SOD2 Ala-9Val polymorphism with the risk for RA was observed $[21,22]$ but an association of SOD2 -9Val/Val genotype with more severe radiologic outcome was reported [21]. In our study we did not assess disease severity however, we observed no association of SOD2 -9Val/Val and CAT C-262CT or TT genotypes with the presence of bone erosions observed on X-rays of hands and feet (data not shown).

On the other hand, the activity of RA may be modulated by the intensity of the inflammatory processes which are influenced by SNPs in genes coding for the TNF $\alpha$ and iNOS. An association of the number of CCTTT repeats in the NOS2A promoter with a higher risk for RA was observed previously [23,24] but no study investigated the association of this $(\mathrm{CCTTT})_{n}$ repeat with RA activity. In our study NOS2A $(\text { CCTTT })_{n}$ was not significantly associated with disease activity however, the influence of NOS2A $(\text { CCTTT })_{n}$ on the risk for RA was not tested. Among the numerous SNPs in the transcription regulatory region of TNFA, G-308A is the most frequently studied, although its effect is still not completely understood. Some investigators observed a higher TNF $\alpha$ production in the carriers of TNFA -308A allele, while others found no functional significance of this SNP [25-29]. Previous clinical studies investigated the influence of SNPs in TNFA promoter on the severity of RA and reported contradictory results. Most studies suggest an association of TNFA -308A allele with a higher disease severity [30-32], while others found worst radiographic damage in the patients with TNFA -308GG genotype [33]. A more severe disease in the carriers of TNFA -308GA genotype was observed [34] however, in other studies no association of TNFA G-308A allele with the absence of erosions or between bone destruction was reported [28, 35,36]. These latter observations support our data as TNFA G-308A polymorphism did not influence the presence of bone erosions in our RA patient group (data not shown). Nevertheless, we observed that the carriers of TNFA -308A allele had a lower disease activity as compared to the patients with TNFA -308GG genotype. This is a novel finding and is in contrast to the results of previous studies where no association of TNFA G308A polymorphism with disease activity was reported $[32,37]$. However, the differences in mean DAS28 values observed between TNFA -308A and G allele carriers were relatively small and both mean DAS28 values can be considered as moderate disease activity. We found weak linkage disequilibrium between TNFA C-857T and G-308A SNPs however, we observed no association of TNFA C-857T polymorphism with disease activity.

In this study we also investigated if the combination of CAT and TNFA genotypes influenced disease activ- 
ity in RA patients. We observed that the carriers with the combination of CAT -262T and TNFA -308A allele had lower DAS28 values than carriers of either CAT $-262 \mathrm{~T}$ or TNFA $-308 \mathrm{~A}$ allele. When we determined the type of interaction between CAT and TNFA genotypes we observed that OR of the combined effect corresponded to the independent effect of each individual gene. Although mean DAS28 values of both the carriers and non-carriers of CAT -262T and TNFA -308A allele combination can be considered as moderate disease activity, the carriers had higher probability for low disease activity as compared to the non-carriers. The combination of any other studied polymorphisms was not associated with disease activity. To our knowledge the influence of combination of CAT and TNFA genotypes on disease activity has not been studied yet. Little data is published on other genotype combinations that may also modify the capacity for defense against oxidative stress in RA patients. A previous study reported on an association of the interaction of SOD2 -9Val/Val and glutathione S-transferase T1-null genotype with disease severity [21], but this interaction was not tested in our study.

The main bias of our study was the lack of information on the MnSOD, CAT and iNOS enzymes activities and on the TNFA expression and protein levels as sampling strategy did not allow us to perform these analyses. Another bias was that DAS28 values are changing with the disease progression and are altered by the treatment. In our study, the majority of the patients were treated with one or more DMARDs but mean DAS28 values were not significantly different between the treatment groups (data not shown). In a group of RA patients receiving low-dose MTX monotherapy we determined two DAS28 score within three months apart. For this group we calculated the mean DAS28 values over time and observed that these values were similar to the one-timepoint mean DAS28 values of the whole RA cohort. Therefore we assumed that the results of our study were not biased by the fluctuation in disease activity over time. However, our study lacked the assessment of the disease severity, as we only determined the presence or absence of erosions observed on the X-rays of hands and feet, but did not evaluate the X-rays using the Larsen score. Also the female percentage of our study was higher as reported for the RA patients [38]. To overcome this all the statistical analyses were performed separately for the female patients, but the results obtained were similar. The strength of our findings was that they were not biased by age, sex, disease and treatment duration and
RF/anti CCP seropositivity as $p$ values were corrected for these factors. In addition, our study was not biased by genetic heterogeneity since all the patients were recruited in a geographic area with an ethnically homogeneous population and the treatment and the follow up is centralized for all RA patients [39].

In conclusion, our results suggest an association of genetic polymorphisms of the antioxidant enzymes and pro-inflammatory factors with disease activity of RA. Further studies are needed to evaluate if these polymorphisms can be used in clinical practice as biomarkers for good responders to the treatment. As oxidative stress is a hallmark of the inflammation in general our findings could also be of importance for patients suffering from other inflammatory diseases, such as the inflammatory bowel disease, chronic obstructive pulmonary disease and also type 1 and type 2 diabetes. However, further studies investigating not only the genetic polymorphisms, but also the enzymatic activity and/or protein levels are needed to confirm our observations.

\section{Acknowledgements}

The authors wish to thank dr. Tarja Laitinen from Helsinki, Finland for kindly providing control DNA samples with known SOD3 genotype. The authors are grateful to dr. Ruth R Rupreht from the Blood Transfusion Centre, Ljubljana, Slovenia for kindly providing the TNFA -308 TaqMan probes and the control DNA samples. The authors thank dr. Katarina Trebušak Podkrajšek, dr. Maruša Debeljak and Tinka Hovnik for the help with capillary electrophoresis. We wish to acknowledge Mojca Kos-Golja, MD, Sonja Praprotnik, $\mathrm{MD}, \mathrm{PhD}$, Aleš Ambrožič, MD, PhD, Cvetka KastelicKlasinc, MD and Boris Lestan, MD, MSc from the Department of Rheumatology, University Medical Centre Ljubljana, Slovenia for referring the patients. We thank to Milena Pavić-Nikolić for her excellent technical support. We are especially grateful to Snežna Sodin-Šemrl, MS, PhD for the language corrections. This work was financially supported by The Slovenian Research Agency, grant no. PO-0503-0381. The authors declare no conflict of interest.

\section{References}

[1] M. Feldmann, F.M. Brennan and R.N. Maini, Role of cytokines in rheumatoid arthritis, Апnи Rev Immunol 14 (1996), 397-440. 
[2] J.B. Weinberg, Nitric oxide production and nitric oxide synthase type 2 expression by human mononuclear phagocytes: a review, Mol Med 4 (1998), 557-591.

[3] C.H. Woo, T.H. Kim, J.A. Choi, H.C. Ryu, J.E. Lee, H.J. You, Y.S. Bae and J.H. Kim, Inhibition of receptor internalization attenuates the TNFalpha-induced ROS generation in nonphagocytic cells, Biochem Biophys Res Commun 351 (2006), 972-978.

[4] B. Halliwell, Oxygen radicals, nitric oxide and human inflammatory joint disease, Ann Rheum Dis 54 (1995), 505-510.

[5] C.A. Hitchon and H.S. El-Gabalawy, Oxidation in rheumatoid arthritis, Arthritis Res Ther 6 (2004), 265-278.

[6] S. Shimoda-Matsubayashi, H. Matsumine, T. Kobayashi, Y. Nakagawa-Hattori, Y. Shimizu and Y. Mizuno, Structural dimorphism in the mitochondrial targeting sequence in the human manganese superoxide dismutase gene. A predictive evidence for conformational change to influence mitochondrial transport and a study of allelic association in Parkinson's disease, Biochem Biophys Res Commun 226 (1996), 561-565.

[7] R.J. Folz, L. Peno-Green and J.D. Crapo, Identification of a homozygous missense mutation (Arg to Gly) in the critical binding region of the human EC-SOD gene (SOD3) and its association with dramatically increased serum enzyme levels, Hum Mol Genet 3 (1994), 2251-2254.

[8] L. Forsberg, L. Lyrenas, U. de Faire and R. Morgenstern, A common functional C-T substitution polymorphism in the promoter region of the human catalase gene influences transcription factor binding, reporter gene transcription and is correlated to blood catalase levels, Free Radic Biol Med 30 (2001), 500-505.

[9] A.G. Wilson, F.S. di Giovine, A.I. Blakemore and G.W. Duff, Single base polymorphism in the human tumour necrosis factor alpha (TNF alpha) gene detectable by NcoI restriction of PCR product, Hum Mol Genet 1 (1992), 353.

[10] S.M. Herrmann, S. Ricard, V. Nicaud, C. Mallet, D. Arveiler, A. Evans, J.B. Ruidavets, G. Luc, L. Bara, H.J. Parra, O. Poirier and F. Cambien, Polymorphisms of the tumour necrosis factor-alpha gene, coronary heart disease and obesity, Eur $J$ Clin Invest 28 (1998), 59-66.

[11] K.M. Warpeha, W. Xu, L. Liu, I.G. Charles, C.C. Patterson, F. Ah-Fat, S. Harding, P.M. Hart, U. Chakravarthy and A.E. Hughes, Genotyping and functional analysis of a polymorphic (CCTTT)(n) repeat of NOS2A in diabetic retinopathy, Faseb $J 13$ (1999), 1825-1832.

[12] F.C. Arnett, S.M. Edworthy, D.A. Bloch, D.J. McShane, J.F. Fries, N.S. Cooper, L.A. Healey, S.R. Kaplan, M.H. Liang, H.S. Luthra and e. al, The American Rheumatism Association 1987 revised criteria for the classification of rheumatoid arthritis, Arthritis Rheum 31 (1988), 315-324.

[13] M.L. Prevoo, M.A. van 't Hof, H.H. Kuper, M.A. van Leeuwen, L.B. van de Putte and P.L. van Riel, Modified disease activity scores that include twenty-eight-joint counts. Development and validation in a prospective longitudinal study of patients with rheumatoid arthritis, Arthritis Rheum 38 (1995), $44-48$.

[14] S.A. Miller, D.D. Dykes and H.F. Polesky, A simple salting out procedure for extracting DNA from human nucleated cells, Nucleic Acids Res 16 (1988), 1215.

[15] W. Xu, L. Liu, P.C. Emson, C.R. Harrington and I.G. Charles, Evolution of a homopurine-homopyrimidine pentanucleotide repeat sequence upstream of the human inducible nitric oxide synthase gene, Gene 204 (1997), 165-170.
[16] L. Excoffier, G. Laval and S. Schneider, Arlequin ver. 3.0: An integrated software package for population genetics data analysis, Evolutionary Bioinformatics Online 1 (2005), 47-50.

[17] E. Erdfelder, F. Faul and A. Buchner, GPOWER: A general power analysis program, Behavior Research Methods, Instruments, \& Computers 28 (1996), 1-11.

[18] J. Ahn, S. Nowell, S.E. McCann, J. Yu, L. Carter, N.P. Lang, F.F. Kadlubar, L.D. Ratnasinghe and C.B. Ambrosone, Associations between catalase phenotype and genotype: modification by epidemiologic factors, Cancer Epidemiol Biomarkers Prev 15 (2006), 1217-1222.

[19] M. Bastaki, K. Huen, P. Manzanillo, N. Chande, C. Chen, J.R. Balmes, I.B. Tager and N. Holland, Genotype-activity relationship for Mn-superoxide dismutase, glutathione peroxidase 1 and catalase in humans, Pharmacogenet Genomics 16 (2006), 279-286.

[20] A. El-Sohemy, M.C. Cornelis, Y.W. Park and S.C. Bae, Catalase and PPARgamma2 genotype and risk of rheumatoid arthritis in Koreans, Rheumatol Int 26 (2006), 388-392.

[21] D.L. Mattey, A.B. Hassell, P.T. Dawes, P.W. Jones, L. Yengi, J. Alldersea, R.C. Strange and A.A. Fryer, Influence of polymorphism in the manganese superoxide dismutase locus on disease outcome in rheumatoid arthritis: evidence for interaction with glutathione S-transferase genes, Arthritis Rheum $\mathbf{4 3}$ (2000), 859-864.

[22] J.H. Yen, C.J. Chen, W.C. Tsai, C.H. Lin, T.T. Ou, C.J. Hu and H.W. Liu, Manganese superoxide dismutase and cytochrome $\mathrm{P} 450$ 1A1 genes polymorphisms in rheumatoid arthritis in Taiwan, Hum Immunol 64 (2003), 366-373.

[23] M.A. Gonzalez-Gay, J. Llorca, E. Sanchez, M.A. LopezNevot, M.M. Amoli, C. Garcia-Porrua, W.E. Ollier and J. Martin, Inducible but not endothelial nitric oxide synthase polymorphism is associated with susceptibility to rheumatoid arthritis in northwest Spain, Rheumatology (Oxford) 43 (2004), 1182-1185.

[24] M. Pascual, M.A. Lopez-Nevot, R. Caliz, B.P. Koeleman, A. Balsa, D. Pascual-Salcedo and J. Martin, Genetic determinants of rheumatoid arthritis: the inducible nitric oxide synthase (NOS2) gene promoter polymorphism, Genes Immun 3 (2002), 299-301.

[25] A.G. Wilson, J.A. Symons, T.L. McDowell, H.O. McDevitt and G.W. Duff, Effects of a polymorphism in the human tumor necrosis factor alpha promoter on transcriptional activation, Proc Natl Acad Sci U S A 94 (1997), 3195-3199.

[26] K.M. Kroeger, K.S. Carville and L.J. Abraham, The -308 tumor necrosis factor-alpha promoter polymorphism effects transcription, Mol Immunol 34 (1997), 391-399.

[27] E. Louis, D. Franchimont, A. Piron, Y. Gevaert, N. SchaafLafontaine, S. Roland, P. Mahieu, M. Malaise, D. De Groote, R. Louis and J. Belaiche, Tumour necrosis factor (TNF) gene polymorphism influences TNF-alpha production in lipopolysaccharide (LPS)-stimulated whole blood cell culture in healthy humans, Clin Exp Immunol 113 (1998), 401406.

[28] B.M. Brinkman, D. Zuijdeest, E.L. Kaijzel, F.C. Breedveld and C.L. Verweij, Relevance of the tumor necrosis factor alpha (TNF alpha) -308 promoter polymorphism in TNF alpha gene regulation, J Inflamm 46 (1995), 32-41.

[29] B.A. de Jong, R.G. Westendorp, A.M. Bakker and T.W. Huizinga, Polymorphisms in or near tumour necrosis factor (TNF)-gene do not determine levels of endotoxin-induced TNF production, Genes Immun 3 (2002), 25-29.

[30] A.A. Rodriguez-Carreon, J. Zuniga, G. Hernandez-Pacheco, J.M. Rodriguez-Perez, N. Perez-Hernandez, J.V. Montes de 
Oca, M.H. Cardiel, J. Granados and G. Vargas-Alarcon, Tumor necrosis factor-alpha -308 promoter polymorphism contributes independently to HLA alleles in the severity of rheumatoid arthritis in Mexicans, J Autoimmun 24 (2005), 63-68.

[31] D. Khanna, H. Wu, G. Park, V. Gersuk, R.H. Gold, G.T Nepom, W.K. Wong, J.T. Sharp, E.F. Reed, H.E. Paulus and B.P. Tsao, Association of tumor necrosis factor alpha polymorphism, but not the shared epitope, with increased radiographic progression in a seropositive rheumatoid arthritis inception cohort, Arthritis Rheum 54 (2006), 1105-1116.

[32] J.E. Fonseca, J. Cavaleiro, J. Teles, E. Sousa, V.L. Andreozzi, M. Antunes, M.A. Amaral-Turkman, H. Canhao, A.F. Mourao, J. Lopes, J. Caetano-Lopes, P. Weinmann, M. Sobral, P. Nero, M.J. Saavedra, A. Malcata, M. Cruz, R. Melo, A. Brana, L. Miranda, J.V. Patto, A. Barcelos, J.C. da Silva, L.M. Santos, G. Figueiredo, M. Rodrigues, H. Jesus, A. Quintal, T. Carvalho, J.A. da Silva, J. Branco and M.V. Queiroz, Contribution for new genetic markers of rheumatoid arthritis activity and severity: sequencing of the tumor necrosis factor-alpha gene promoter, Arthritis Res Ther 9 (2007), R37.

[33] P. Nemec, M. Pavkova-Goldbergova, M. Stouracova, A. Vasku, M. Soucek and J. Gatterova, Polymorphism in the tumor necrosis factor-alpha gene promoter is associated with severity of rheumatoid arthritis in the Czech population, Clin Rheumatol 27 (2008), 59-65.
[34] J.T. Cvetkovic, S. Wallberg-Jonsson, B. Stegmayr, S. Rantapaa-Dahlqvist and A.K. Lefvert, Susceptibility for and clinical manifestations of rheumatoid arthritis are associated with polymorphisms of the TNF-alpha, IL-1beta, and IL-1Ra genes, J Rheumatol 29 (2002), 212-219.

[35] H. Marotte, P. Farge, P. Gaudin, C. Alexandre, B. Mougin and $\mathrm{P}$. Miossec, The association between periodontal disease and joint destruction in rheumatoid arthritis extends the link between the HLA-DR shared epitope and severity of bone destruction, Ann Rheum Dis 65 (2006), 905-909.

[36] A.G. Wilson, N. de Vries, L.B. van de Putte and G.W. Duff, A tumour necrosis factor alpha polymorphism is not associated with rheumatoid arthritis, Ann Rheum Dis 54 (1995), 601-603.

[37] A. Pawlik, M. Florczak, L. Ostanek, M. Brzosko, I. Brzosko and B.G. Szklarz, TNF-alpha -308 promoter polymorphism in patients with rheumatoid arthritis, Scand J Rheumatol 34 (2005), 22-26.

[38] J.M. Grossman and E. Brahn, Rheumatoid arthritis: current clinical and research directions, J Womens Health 6 (1997), 627-638.

[39] B. Vidan-Jeras, B. Jurca, V. Dolzan, M. Jeras, K. Breskvar and M. Bohinjec, Caucasian Slovenian normal, in: HLA 1998, D. Gjertson and P. Terasaki eds, American society for histocompatibility and immunogenetics, Lenexa, 1998, pp. 180-181. 


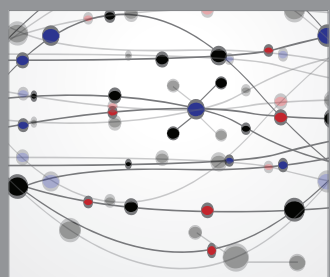

The Scientific World Journal
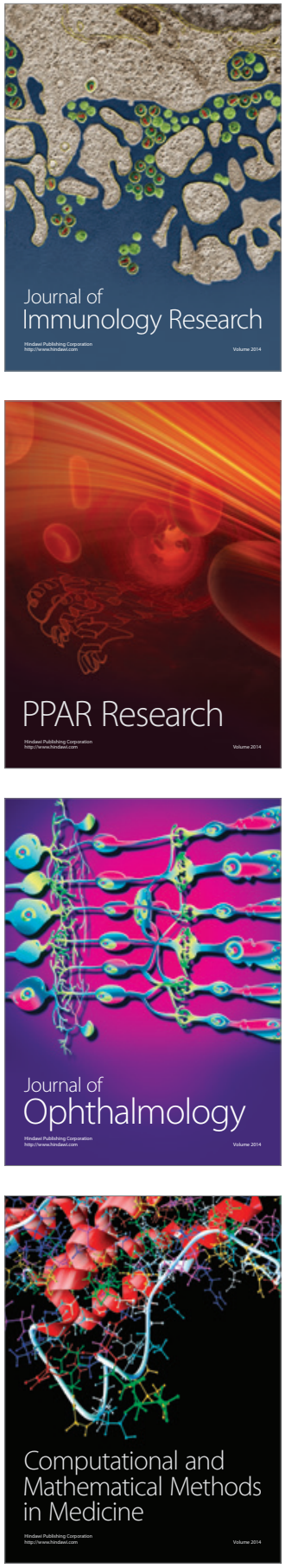

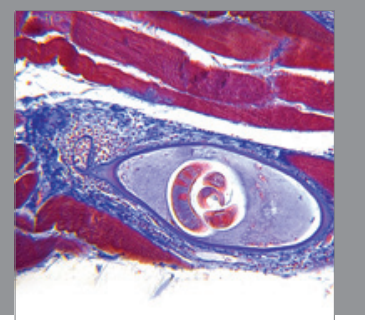

Gastroenterology

Research and Practice
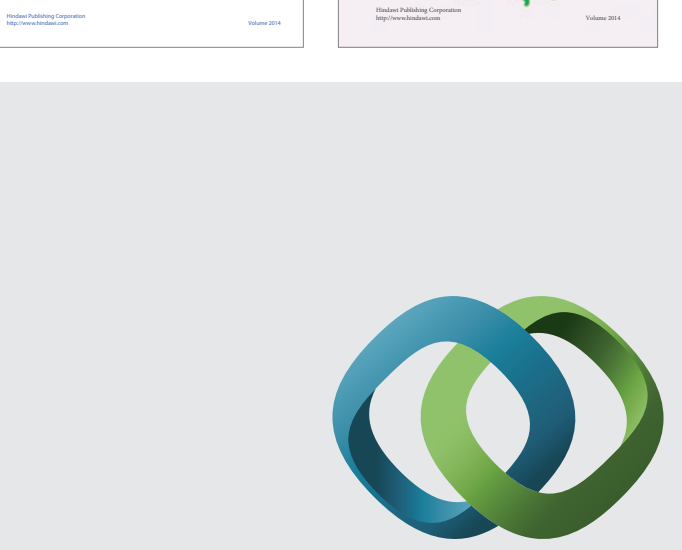

\section{Hindawi}

Submit your manuscripts at

http://www.hindawi.com
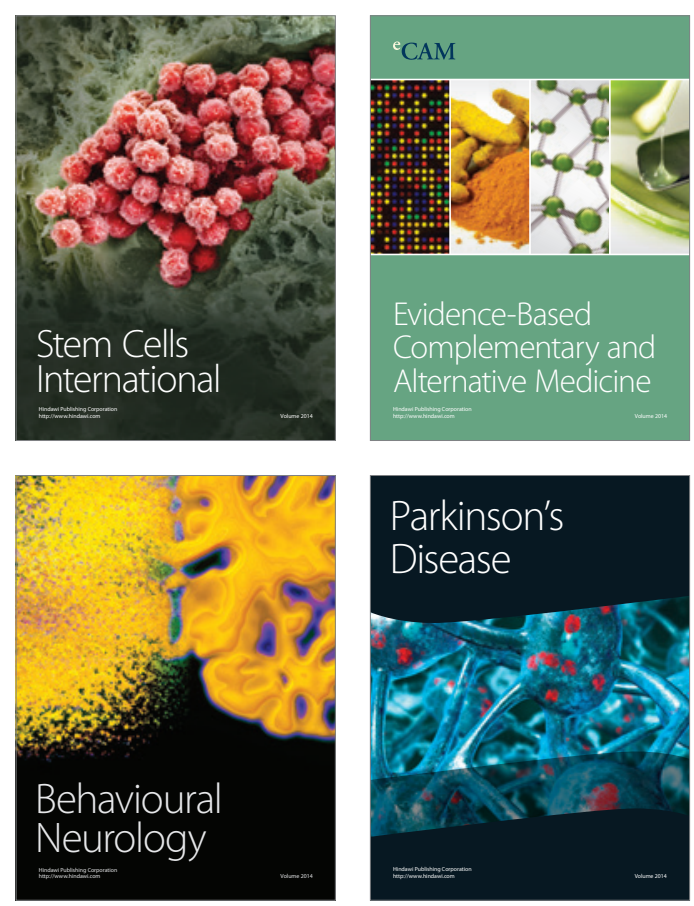

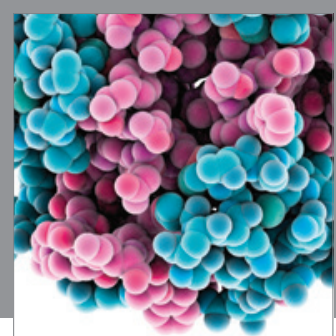

Journal of
Diabetes Research

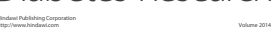

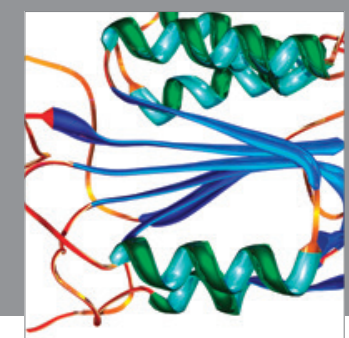

Disease Markers
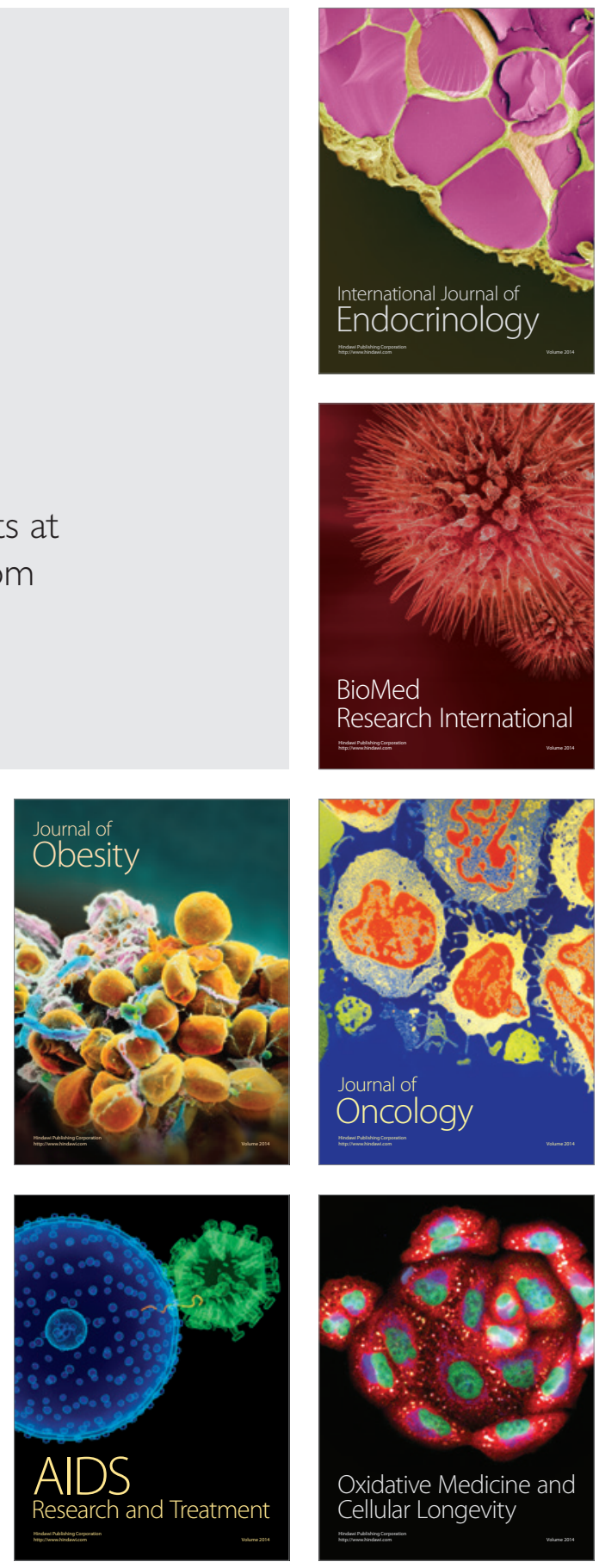